\title{
Competition in the healthcare sector: a missing dimension
}

\author{
Peter Zweifel ${ }^{1}$
}

Published online: 8 August 2016

(c) Springer-Verlag Berlin Heidelberg 2016

In a recent issue of this journal, [1] presented a management summary of the comprehensive and insightful report prepared by the expert panel on effective ways of investing in health (EXPH) entitled, competition among health care providers-investigating policy options in the European Union. As their backfoil, EXPH use the familiar tripolar model with a payor (potential) patients, and healthcare providers (p. 16). They also correctly emphasize that competition is a means to an end, i.e., to achieving a set of goals a country's citizens agree upon, without however detailing them (p. 12). The objective of this editorial is to introduce the notion of competition for the position of the 'payor pole' and to link the institutional choice of the 'payor pole' to the contribution that competition in the healthcare sector may make to the achievement of a defined set of goals.

\section{Six criteria of performance applied to the healthcare sector}

Starting with the goals, the economic literature is dominated by a discussion of criteria such as full employment and price stability, which are of little relevance to health care. Thankfully, the website Answers.com takes a microeconomic approach, citing efficiency and equity while also emphasizing innovation (see also [2]). Evidently, one would want to distinguish between static efficiency (meaning that goods and services are produced at minimum cost and that the composition of these goods and

Peter Zweifel

peter.zweifel@uzh.ch

Emeritus, University of Zurich, Zurich, Switzerland services is in accordance with consumer preferences) and dynamic efficiency (meaning that process innovation keeps lowering the minimum cost benchmark while product innovation continues to improve adaptation to consumer preferences). A fifth criterion straddles efficiency and equity. It is the absence of rents, i.e., incomes earned that are not necessary to ensure the attainment of the other four criteria. Such an income distribution (between individuals able to work) is commonly deemed equitable. The sixth criterion is equity proper, which is usually interpreted as non-exclusion from access to the goods and services produced by the economy, to be achieved by redistribution of incomes.

The idea here is to apply these six criteria to the healthcare sector. While typically resisted by the health professions, this can be justified on at least two grounds. For one, with health claiming more than $10 \%$ of GDP in most industrial countries, failure to meet these criteria detracts from the economy's overall ability to perform well. Second, the cost of health care ultimately is not borne by government or social insurance but by citizens through their taxes and contributions. To the extent that they want to see the six criteria satisfied in the general economy, there is no reason to apply different ones to health care.

\section{Competition for the 'payor pole'}

With the set of goals to be achieved by competition in health care defined, one can turn to the missing dimension, competition for the 'payor' pole. First, however, one needs to ask a fundamental question that is rarely addressed, why does this third pole exist at all? One answer is that the informational asymmetry between a potential patient (acting as the principal) and the agent (the healthcare provider) 
is so marked that the principal-agent (PA) model does not apply. Contrary to their dealings with architects and lawyers (say), consumers are hardly able to identify, let alone negotiate an optimal PA contract that would meet (at least some of) the six criteria mentioned [8]. In health care, this creates a market for intermediaries who can identify and/or negotiate such a contract on behalf of potential patients. They compete for the 'payor pole' in the tripolar modelwith consequences for competition in the healthcare sector that are often overlooked.

Starting with the most decentralized variant, employers can take on the task of negotiating with healthcare providers (as they did e.g., in ex-Yugoslavia). Having experience in implementing PA contracts with their employees, they are well poised to perform this function. Next are competitive health insurers (regardless of whether private as e.g., in the United States or predominantly social as e.g., in The Netherlands), who dispose of administrative data permitting them to devise PA contracts with optimal incentives. They are followed by local government (e.g., Sweden's health districts), which in principle have the authority to collect the information necessary for structuring contracts with providers in the interest of their constituencies. As to centralized alternatives, the medical association can serve as the intermediary, being able to even monitor the performance of its members; it was in charge e.g., in Germany (at the regional level) until the 1960s. A more common variant is uniform social health insurance (as e.g., in Canada), which as a monopsony could simply impose contracts benefiting the citizenry. This is of course also true of national government, with the UK National Health Service (NHS) constituting the prime example. In sum, there are no less than six types of intermediaries potentially competing for the 'payor pole', with the cards stacked in favor of the national government, who is both intermediary and regulator setting the rules of the game.

\section{The effect of competition in healthcare depends on who occupies the 'payor pole'}

Evidently, the six intermediaries distinguished all have the capability of identifying and/or negotiating contracts with healthcare providers that are optimal for (groups of) consumers. However, they turn out to differ substantially w.r.t. their incentives to make competition in the healthcare sector contribute to the six goals defined above.

\section{Production at minimum cost}

Competition is known to ensure that a given good or service is produced at minimum cost. Employers can be expected to negotiate contracts with providers for delivery of a defined set of healthcare services at minimum cost because they themselves are under pressure of competition for (productive) workers. However, employees typically are afraid of health-related information leaking to the employer, one reason for e.g., the U.S. Kaiser Company to farm out health care to Kaiser Permanente [4]. Health insurers competing for members have a similar incentive, yet extensive public regulation of products and contributions combined with a tradition of collusion has been weakening it considerably. As to local government, politicians and administrators in charge are also somewhat interested in production at minimum cost because citizens can compare the performance of jurisdictions; however, their voting behavior rarely depends on the cost of health care alone. A medical association, being a cartel, has no interest in competition between healthcare providers; after all, cost minimization would lower their members' incomes. The representatives of social health insurance tend to eschew tough negotiations with providers; in the absence of competition, they have the leeway to pursue a quiet life. The incentives of national governments are clear. Being exposed to a degree of competition through the performance of the general economy, they hope to use competition to lower that part of healthcare expenditure (HCE) that falls on their budget. Yet, as shown below, optimal HCE brought about by competition does not imply low HCE.

\section{Adaptation to patient preferences}

Competition is also known for fostering Pareto efficiency [5, ch. 16.2], which means that the structure of goods and services (produced at minimal cost) matches the structure of consumer preferences (in more technical terms, the marginal rate of substitution in preference equals the marginal rate of transformation in production). Employers acting as intermediaries would have to respect patient preferences in their negotiations to the extent that they risk losing productive workers for failure to do so. Patient preferences of course drive competing health insurers in their quest for clientele. They are heeded at a more aggregate level by local government, although voters are again unlikely to judge its performance on this criterion alone. A medical association will want to encourage its members to respect patient preferences because their neglect would trigger search for another physician and with it, competition between members of the cartel. In the absence of competitive pressure, adaptation to patient preferences is not high on the agenda of uniform social health insurance. In fact, patient preferences are often seen as leading to an 'uncontrolled' increase in HCE that is to be avoided. The same concern preoccupies national government. Yet recall that Pareto optimality also requires the ratio, marginal utility/marginal cost to be equal across 
goods and services. If citizens value (extra) health care very highly, it should be provided up to a point where its marginal cost is also high, resulting in high HCE. With their focus on low HCE, social health insurance and national government therefore risk to violate an important optimality criterion.

\section{Process innovation}

This is the dynamic counterpart of criterion no. 1. It means incorporating technological change for production at ever lower cost, a rather unpopular proposition to those working in the industry concerned ("the same as before, but faster please"). Although infrequently cited, the contribution of competition to process innovation is important, as evidenced by e.g., the auto industry, where international competition has led to a given type of car being produced within hours rather than days. The two intermediaries who would be keen to benefit from process innovation in health care are employers (who are used to international purchasing) and competitive health insurers (who however are often mandated to purchase domestically, which shuts out international competition). By way of contrast, a medical association, a uniform social health insurer, and both levels of government are protected from international competition, permitting them to largely neglect process innovation.

\section{Product innovation}

This type of innovation is defined as the addition of new attributes (or a new combination of them) to a good or service which triggers an increase in the willingness to pay (WTP) on the part of consumers. This causes a shift the consumer's optimum, defined by the equality of the ratio, marginal utility/price across goods and services, and since WTP increases with marginal utility, the innovative alternative may also cost more [6]. The impact of competition on product innovation is subject to debate because it may reduce the returns to innovative effort (see [3] for a survey of the arguments). In the case of healthcare providers, who are predominantly adopters of product innovation, competition may safely be assumed to speed up adoption. Employers and competitive health insurers acting as intermediaries can be counted upon to weigh the increase in WTP of their clientele against the increase in contributions. To the extent that there is Tiebout competition between local governments [7], they will act in the same way. A medical association is unambiguously in favor of product innovation (without concern for its cost implications) because it increases the demand for its members' services. Incentives for uniform social health insurance and central government are exactly opposite. For these institutions, the fact that product innovations go along with an increase in $\mathrm{HCE}$ threatening their financial equilibrium is of crucial importance, as evidenced by the need to reduce the backlog of cases waiting for assessment by NICE, the UK National Institute for Health and Clinical Excellence [7].

\section{Absence of economic rent}

This criterion is decisive for the attainment of the other four. As long as producers (healthcare providers in the present context) can earn income in excess of what is necessary to induce them to meet criteria no. $1-4$, they have little incentive to make the effort. Competition is known to drive out economic rent, at least in the long run [5, ch. 7.2]. As to the six intermediaries distinguished, it is again the pressure of competition they themselves face that may make them favor competition as a means to squeeze out economic rent in the healthcare sector. However, this would require opening healthcare markets to international competition in particular. Even employers and competitive health insurers may loath to take on the myriad of legislation designed to protect domestic producers, while a medical association stands to defend it. A uniform health insurer and both levels of government are unlikely to take the initiative either in view of their domestic orientation.

\section{Equity}

While opinions with regard to the precise meaning of equity differ greatly, there is a general consensus that it calls for income redistribution. Admittedly, competition does not foster redistribution; in particular, it is not compatible with cross-subsidization in favor of poor consumers because a competitor would siphon off the rich consumers by offering them a lower price. This argument implies that employers and competitive health insurers cannot be expected to perform redistribution in the healthcare sector. A medical association may encourage its members to perform it because e.g., devoting more time to some patients to the detriment of others cannot be easily observed. It is the uniform social health insurer and both levels of government who are best able to take on this function. Solidarity calls for social health insurance to charge the same contribution regardless of the individual's risk status while possibly grading it to income, while redistribution of incomes has become the primary mission of government to begin with.

\section{Conclusions}

When it comes to assessing the nature and effects of competition on the performance of the healthcare sector, the dimensions of 'performance' need to be defined first, 
something that is missing from the recent contribution by [1]. The alternative proposed in this editorial is to adopt criteria known from the theory of economic policy, viz. the static ones of production at minimum cost and adaptation to consumer preferences, the dynamic ones of process innovation and product innovation, absence of economic rent, and equity (see also [9]). Next, it is appropriate to also incorporate competition for the 'payor pole' in the familiar tripolar model of the healthcare sector alongside (potential) patients and providers. It turns out that contrary to conventional principal-agent theory, consumers acting as principals are unlikely to be capable of identifying (let alone negotiating) optimal contracts with healthcare providers acting as agents. This creates competition for the role of an intermediary promising to at least mitigate this market failure and hence competition for the 'payor pole'. Employers and competing health insurers are found to differ greatly from a medical association, uniform social health insurance, and central government in terms of their incentives to use competition as a means of improving the performance of the healthcare sector, with local government occupying an intermediate position. In sum, competition in health care takes on very different forms, depending on the intermediary who occupies the "payor pole' and the extent to which it is exposed especially to international competition.

\section{References}

1. Barros, P.P., Brower, W.B.F., Thomson, S., et al.: Competition among health care providers: helpful or harmful? Eur. J. Health Econ. 17(3), 223-229 (2016)

2. Fritsch, H.J., Wein, T., Ewers, M.: Marktversagen und Wirtschaftspolitik. Mikroökonomische Grundlagen staatlichen Handelns (market failure and economic policy: microeconomic foundations of governmental activity), 7th edn. Munich, Vahlen (2007)

3. Gilbert, R.: Looking for Mr. Schumpeter: where are we in the competition-innovation debate? In: NBER (ed.) Innovation policy and the economy, vol. 6, pp. 159-215. National Bureau of Economic Research, New York (2006)

4. Hendricks, R.: A model for national health care: the history of Kaiser Permanente, pp. 13-17. Rutgers University Press, New Brunswick (1993)

5. Hirshleifer, J., Glazer, A., Hirshleifer, D.: Price theory and applications. Decisions, markets, and information, vol. 7. Cambridge University Press, Cambridge (2005)

6. Lancaster, K.J.: A new approach to consumer theory. J. Polit. Econ. 74(2), 132-157 (1966)

7. NICE Triennial Review Team: Triennial report. Department of Health, Assurance Division, London (2015)

8. Tiebout, C.M.: A pure theory of local expenditures. J. Polit. Econ. 64(5), 416-424 (1956)

9. Zweifel, P.: A novel way to compare health care systems and to assess their potential competitiveness. Econ. Aff. 36(2), 155-167 (2016) 